\title{
The detrimental effects of obstetric evacuation on Aboriginal women's health
}

\author{
Ann Marie Corrado \\ Faculty Reviewer: Debbie Laliberte Rudman, PhD, OT Reg. (Ont.) (School of Occupational Therapy)
}

\section{ABSTRACT}

In Western society, many colonial practices, such as the removal of Aboriginal women from their communities prior to birth, still detrimentally affects Aboriginal peoples' lives. Health Canada's evacuation policy for pregnant Aboriginal women living in rural and remote areas involves nurses, who are employed by the federal government, coordinating the transfer of all pregnant women to urban cities at 36-38 weeks gestational age to await the birth of their baby. ${ }^{1}$ The policy states that it is founded on concerns for the wellbeing of Aboriginal women, in an attempt to "curb First Nations' child and maternal mortality rates". ${ }^{1}$ However, there is a need to problematize the practice of obstetric evacuation given its colonial roots and its impact on Aboriginal women. The objective of this review paper is to explore and bring awareness to some of the consequences of Canada's evacuation policy for pregnant Aboriginal women who live in rural and remote regions. More specifically, this paper, drawing on ethnographic research previously conducted with Canadian Aboriginal women on their lived experiences of prenatal care and birth, will examine the lack of social support, loss of control, and lack of culturally competent care that Aboriginal women face. The findings demonstrate an urgent need for policy makers to also consider the lived experience of Aboriginal women when making decisions that impact their health.

\section{INTRODUCTION}

Significant health disparities between Aboriginal peoples and the general Canadian population are well documented., ${ }^{2,3}$ Health disparities, such as lower life expectancy and higher rates of chronic diseases, ${ }^{2}$ are rooted in colonialism, whereby the oppressive policies of European settlers led to the forced assimilation of $\mathrm{Ab}$ original peoples. ${ }^{3}$ These policies included Aboriginal peoples being required to admit their children into residential schools and giving up their land. ${ }^{3}$ This paper focuses specifically on the obstetric evacuation policy as part of these practices.

Prior to colonialism, Aboriginal communities had developed approaches to supporting women to give birth in their communities, usually assisted by family members and midwives. ${ }^{4}$ Health care delivery to Aboriginal peoples started being formalized in 1867 through the British North America Act which granted the federal government authority over "Indians and lands reserved for Indians". ${ }^{1}$ Nine years later, the Indian Act gave the colonizing forces control over the location and living conditions for Aboriginal peoples, and Indian agents were given the job of "ensuring First Nations people became 'civilized' enough to 'assimilate' into the broader Euro-Canadian society". Eventually, the need to protect Euro-Canadians from the spread of communicable diseases led to the federal government assuming responsibility for delivering public health services to Aboriginals living on reserves. ${ }^{1}$

The colonizers' control over health resulted in an impactful shift in the way Aboriginal peoples received healthcare, whereby the government's actions undermined culturally based concepts of health. ${ }^{5}$ In the late 19th century, for example, Inuit women began giving birth in newly established nursing stations, assisted by nurses or midwives employed by the federal government. ${ }^{6}$ Over time Aboriginal peoples' traditional birthing practices and care providers in their communities were eliminated and "women's bodies thus became a site upon which colonial goals of civilization and assimilation could be realized". ${ }^{1}$ Existing research highlights the imperative need to examine how obstetric evacuation affects $\mathrm{Ab}$ original women's health, particularly in relation to social support, control, and care that respects historical traditions.

\section{SOCIAL SUPPORT}

The lack of social support that Aboriginal women experience as a result of obstetric evacuation is related to separation from their families and communities, as well as a lack of support from medical professionals during labour and delivery. For example, in a study of two communities in the central Canadian Arctic, the most frequently identified stressor by women as a result of evacuation, is "the enforced separation from family...and the community". " Unfortunately, the lack of social support from partners, family and the wider community cause many women to experience stress, anxiety and fear leading up to birth. One woman from Bella Bella, a small First Nations community in British Columbia, shared "I really didn't want to leave because my whole family is here and I wanted them to be around". 9

The lack of social support Aboriginal women experience prior to birth is problematic as "neither the public nor care providers fully understand the long term, highly significant benefits of a well-supported birth". ${ }^{10}$ In addition, researchers have consistently found that women who do not have social support have less positive experiences of birth, while those with social support "experience fewer childbirth complications and less postpartum depression"." Unfortunately, Aboriginal women have less social support from family members because of obstetric evacuation and they also perceive a lack of support from hospital staff.

Many Aboriginal women feel that health professionals are not 
supportive during labour. For example, in the same study done in the Canadian Arctic, the women expressed getting very little support from the nursing staff during labour. ${ }^{7}$ Research examining continuous support during childbirth by a medical professional or family member suggest that social support results in more spontaneous vaginal births and women who are more satisfied with their birth experience. ${ }^{2}$ Therefore, it is critical that the evacuation policy places greater emphasis on the role urban hospital staff play in providing support to Aboriginal women as they may be the only ones present with these women during labour and delivery. Otherwise the policy must be modified to financially support the presence of family members during labor and delivery.

\section{LOSS OF CONTROL}

Research also demonstrates that Aboriginal women from the North often experience a loss of agency when they are given no choice in where and how they will deliver. Having agency is important for all individuals as "lack of control over important dimensions of living, in itself contributes to ill health". ${ }^{13}$ Although quantitative data have supported the evacuation approach by showing reduced mortality rates among mothers and babies, ${ }^{1}$ critics have asserted that the use of specific statistics that show improvement is simply an attempt to support assimilation by discouraging $\mathrm{Ab}$ original birthing practices and emphasizing the superiority of the biomedical model. ${ }^{1}$

After the policy was put into place, fewer midwives were hired in relation to community nurses and the shift in staffing resulted in nurses no longer feeling prepared to provide care to women during labour and delivery, ${ }^{7}$ leaving expectant mothers with almost no choice but to deliver outside their community. One mother shared her thoughts about the lack of staffing in the community and its relation to safety when she stated, "when you are pregnant you want to hear that it's going to be safe...I wasn't hearing the things I wanted to hear so that's what made me really scared to have my baby here". ${ }^{9}$ The lack of choices and control women have over birth is problematic because it increases anxiety during pregnancy, which is associated with "shorted gestation and has adverse implications for fetal neurodevelopment and child outcomes". ${ }^{14}$ Therefore, the mother's mental health as well as the baby's physical health will suffer with a lack of agency on where to deliver.

\section{CULTURALLY COMPETENT CARE}

Another consequence of the evacuation policy is that women often do not receive culturally competent care that is congruent with their culture. ${ }^{15}$ Some researchers found that many women experience "estrangement from larger cultural norms surrounding birth" such as traditional gatherings to honour the new baby after birth and elders wrapping a piece of umbilical cord in leather for the baby. ${ }^{16}$ It is imperative that urban centres and providers enhance cultural competence as "care that is congruent with the patient's culture promotes not only the patient's health but also the patient's sense of well-being because well-being is a culturally determined phenomenon". ${ }^{15}$ Thus, steps can be taken to respect the culture of
Aboriginal women who do give birth in urban centres away from their homes through integrating traditions that are meaningful to women and thereby enhancing sense of well-being as they deliver their babies in an unfamiliar environment.

\section{CONCLUSION}

Canada's obstetric evacuation policy for Aboriginal women has detrimental effects on health as mothers must travel alone to unknown cities, where they are not equal partners in the decision making regarding the birth of their babies and the care they receive does not honour their cultural traditions. While quantitative indicators such as infant mortality rates are important to measure and address, a more holistic policy approach would also attend to the lived experiences of women who undergo evacuation and the negative consequences these events can have on their health. An improved obstetric evacuation policy should address the need to enhance resources for local delivery so as to both minimize infant mortality and promote women's well-being. Ideally, policy makers should focus on recruitment and retention of culturally competent staff in communities serving these women so that all women, regardless of culture, can have a well-supported birth that gives them the opportunity to meaningfully participate and incorporate their preferences.

\section{REFERENCES}

1. Lawford K, Giles A. Marginalization and coercion: Canada's evacuation policy for pregnant First Nations women who live on reserve in rural and remote regions. J Aborig Indigen Commun Health. 2012; 10(3):327-340.

2. Frohlick KL, Ross N, Richmond C. Health disparities in Canada today: Some evidence and a theoretical framework. Health Policy. 2006 Dec;79(2-3):132-43.

3. Germov J, Hornosty J. Second Opinion: An Introduction to Health Sociology. Canada: Oxford University Press; 2012.

4. Couchie C, Sanderson S. A report on best practices for returning birth to rural and remote Aboriginal communities. J Obstet Gynaecol Can. 2007 Mar;29(3):250-260.

5. Kulig JC, Williams AM. Health in Rural Canada. Toronto: UBC Press; 2012 .

6. Douglas, VK. Childbirth among the Canadian Inuit: a review of the clinical and cultural literature. Int J Circumpolar Health. $2006 \mathrm{Feb}$ 8;4(2):117-32.

7. Chamberlain M, Barclay K. Psychosocial costs of transferring indigenous women from their community for birth. Midwifery. 2000 Jun;16(2):116-22.

8. Kornelsen J, Grzybowski S. Safety and community: the maternity care needs of rural parturient women. J Obstet Gynaecol. 2005 Jun;27(6):247-254.

9. Kornelsen J, Kotaska A, Waterfall P, et al. Alienation and resilience: the dynamics of birth outside their community for rural First Nations women. J Aborig Health. 2011 Mar 20;7(1):55-64.

10. Humenick SS. The life-changing significance of normal birth. J Perinat Educ. 2006; 15(4):1-3.

11. Gjerdingen DK, Frogberg DG, Fontaine P. The effects of social support on women's health during pregnancy, labor and delivery, and the postpartum period. Fam Med. 1991 Jul;23(5):370-375.

12. Hodnett ED, Gates S, Hofmeyr G, et al. Continuous support for women during childbirth. Cochrane Database Syst Rev. 2013 Jul 15;7(2):1-100.

13. Seear M. An introduction to international health. (pp.415-437). Toronto: Canadian Scholars' Press Inc; 2012. 415-437 p.

14. Schetter CD, Tanner L. Anxiety, depression and stress in pregnancy: implications for mothers, children, research, and practice. Curr Opin Psychiatry. 2012 Mar;25(2):141-148.

15. Narayan MC. Six steps toward cultural competence: a clinician's guide. Home Health Care Manag Pract. 2001 Dec 1;14(1) 40-48.

16. Driscoll T, Kelly L, Payne L, et al. Delivering away from home: the perinatal experiences of First Nations women in Northwes ern Ontario. Can J Rural Med. 2011; 16(4):126-130. 